
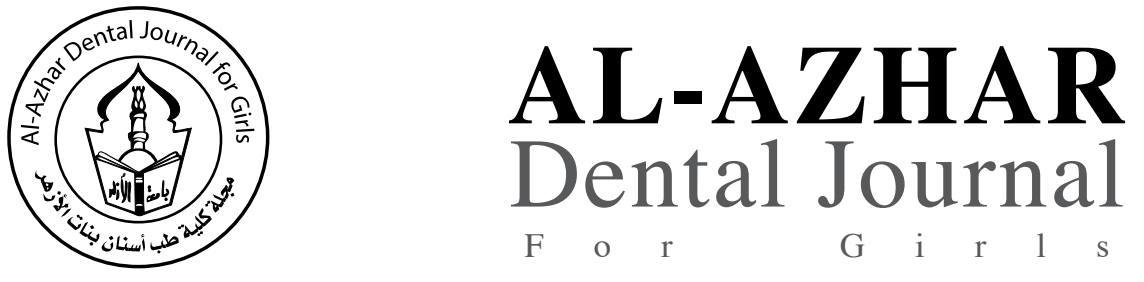

The Official Publication of The Faculty of Dental Medicine For Girls, Al-Azhar University Cairo, Egypt.

ADJ-for Grils, Vol. 4, No. 2, April (2017) — PP. 179:188

\title{
Remineralization of Early Carious Lesions using Biomimetic Self- assembling Peptides Versus Fluoride agent. (In vitro and In vivo study)
}

\author{
Noha Ibrahim Metwally ${ }^{(1)}$, Maha Ahmed Niazy ${ }^{(2)}$ and Magda Ahmed El-Malt ${ }^{(3)}$
}

Codex : 21/1704

dentaljournal.forgirls@yahoo.com
Paper was extracted from Doctor thesis entitled as "Remineralization of Early Carious Lesions using Biomimetic Selfassembling Peptides Versus Fluoride agent (In vitro and In vivo study)"

\section{KEYWORDS}

Remineralization,

self-assembling peptides,

Biomineralization,

Fluoride varnish,

AFM, Early carious lesions.

\begin{abstract}
Objective: The purpose of this study is to evaluate the remineralization potential of the self-assembling peptideP11-4 (Curodont repair) versus highly concentrated fluoride agent (Enamelast) after single \& double applications (Atomic Force Microscopy study) and to evaluate the clinical efficacy of both agents in patients with early carious lesions. Materials and methods: Twenty children ranging from 10-16 years of age were selected with at least 2 white lesions (WSL) detected clinically on the buccal surface of permanent anterior teeth, one on each side. Patients were randomly assigned into 2 groups according to the re-mineralizing agent applied. $\mathbf{A}_{\mathbf{1}}: 20 \mathrm{WSL}$ re-mineralized with Curodont. $\mathbf{A}_{2}: 20$ WSL re-mineralized with Fluoride varnish. Each group was further subdivided into 2 subgroups according to the number of applications with $\left(A_{1} B_{1}\right): 10$ WSL treated with Curodont single application, $\left(A_{1} B_{2}\right): 10$ WSL treated with Curodont double applications, $\left(\mathrm{A}_{2} \mathrm{~B}_{1}\right)$ : $10 \mathrm{WSL}$ treated with fluoride single application and $\left(\mathrm{A}_{2} \mathrm{~B}_{2}\right)$ : $10 \mathrm{WSL}$ treated with fluoride double applications. Also this study was carried on 40 freshly extracted young upper or lower premolars. Teeth were extracted from patients ranging from 14 to 20 years, for orthodontic purpose. Forty enamel samples were prepared from teeth and then examined before and after demineralization and after remineralization with Atomic Force Microscopy (AFM). Results: Both remineralizing agents showed decrease in enamel average roughness after remineralization, however group ( $\mathrm{A}_{1}$ : Curodont) showed the lowest results. Both groups show gradual decrease in the International Caries Detection Assessment System scores (ICDAS) from the base line to reach the lowest level after 6 months. The best results of ICDAS scores were recorded in subgroup $\left(\mathrm{A}_{1} \mathrm{~B}_{2}\right.$ : Curodont double application). Both subgroups of curodont repair revealed an extremely significant higher percent increase of radiodensity percentage in comparison to fluoride subgroups. No significant difference between the 2 remineralizaing agents on the $\mathrm{pH}$ of saliva. Conclusion: Self-assembling peptides (Curodont repair) was successful as a remineralizing agent in young permanent teeth with white spot lesions.
\end{abstract}

1. Assistant Lecturer of Pedodontics and Oral Dental Health, Faculty of Dental Medicine for Girls, Al-Azhar University.

2. Professor of Operative Dentistry, and Former Vice Dean, Faculty of Dental Medicine for Girls, Al-Azhar University.

3. Associate Professor of Pedodontics and Oral Dental Health, Faculty of Dental Medicine for Girls, Al- Azhar University. 


\section{INTRODUCTION}

Dental caries continues to plague most of the world's population. Thus, more effective public health and preventive measures are needed to address this worldwide problem. The past decades have led to major changes in restorative and preventive dentistry. Various investigators reported that early carious lesions can be re-mineralized from saliva. This process was studied in details in laboratory experiments and in clinical trials ${ }^{(1-2)}$.

In caries prevention, most protocols are still built around fluoride, although improving oral hygiene, sugar substitutes and antimicrobials are also part of the more comprehensive packages of non-invasive care. Re-mineralization of superficial enamel lesions is well documented in hundreds of studies which led to the conclusion that the caries preventive effect of fluoride is beyond any doubt ${ }^{(3)}$.

The fluoride ion has a preventive effect against caries. It modifies bacterial metabolism in dental plaque by inhibiting some enzyme processes, inhibits the production of acids by acting on the composition of the bacterial flora or on the metabolic activity of micro-organisms, and reduces demineralization and favors the re-mineralization of early carious lesions. However, fluoride's mechanism of action is only topical within a reach of few $\mu \mathrm{m}$ into enamel respectively into the subsurface of carious lesion $^{(3-4)}$.

Enamel caries is probably the most common of all skeletal tissue pathologies, presenting as progressive subsurface demineralization (mineral loss) and ultimately resulting in mechanical failure and cavitations. Demineralization of enamel results first in a sub-clinical lesion and eventually in the production of a white spot lesion (WSL) ${ }^{(5)}$.Demineralized enamel, the precursor to caries formation, can be attributed to fixed orthodontic appliances and prolonged exposure to bacterial plaque. Bacterial plaque promotes the accumulation of acidic by- products and demineralization that leads to successive changes in optical properties of subsurface demineralized enamel ${ }^{(6)}$. At this stage, clinicians frequently elect to monitor lesion appearance, perhaps after the use of topical fluorides, to determine whether or not the lesion will progress, in which case a restoration would then be placed ${ }^{(7)}$.

Recently, oligomeric $\beta$-sheet-forming peptides that spontaneously form three dimensional fibrillar scaffolds in response to specific environmental triggers have been used in skeletal tissue engineering; including the treatment/prevention of dental caries. Peptide treatment significantly increased net mineral gain due to a combined effect of increased mineral gain and inhibition of mineral loss. In addition, the self-assembling peptide was shown to induce hydroxyapatite nucleation de-novo ${ }^{(8-9)}$.

The self-assembling peptide (SAP) P11-4 diffuses deeply into the subsurface body of the carious lesion where it forms a 3-dimensional matrix. $\mathrm{Ca}^{2+}$ and $\mathrm{PO}^{3-}$ ions, the components of enamel, are sufficiently available from the patient's saliva and attach to the matrix, inducing de-novo formation of hydroxyapatite (HA) crystals ${ }^{(10)}$. Accordingly, nonsurgical intervention promoting defect bio-mineralization or regeneration at the white spot lesion stage would remove the need to "wait and see" and avoid the ultimate excavation of the tooth to place a restoration $^{(11)}$.

Several clinical trials have compared the safety, clinical applicability, re-mineralization efficacy and patient satisfaction of using P11-4 (Curodont ${ }^{\mathrm{TM}}$ Repair) in non-invasive treatment of early carious lesions with fluoride ,showing superiority of Curodont in all aspects versus the gold-standard fluoride $^{(12-14)}$.

Therefore, the present study aimed to evaluate the re-mineralization efficacy of commercially available self-assembling peptide P11-4 in respect to a fluoride varnish both in vitro and in vivo. 


\section{MATERIALS AND METHODS}

Invitro study: A total of 40 freshly extracted young upper or lower premolars were used. Teeth were extracted from patients ranging from 14 to 20 years, for orthodontic purpose ${ }^{(15)}$, and the patients were informed about and consented to the use of their teeth. Teeth were obtained from the orthodontic clinic, Faculty of Dental Medicine for Girls, AlAzhar University.

The selected teeth should be free of caries and defects ${ }^{(16)}$. Any teeth with defects, erosions or micro-cracks on their enamel surfaces, or visible stains on the facial surfaces were excluded ${ }^{(17)}$.

The teeth were then manually cleaned of soft tissue debris (hand scaler and polishing brush) and disinfected in 5\% sodium hypochlorite solution for 1 hour. The teeth were then rinsed and stored in artificial saliva which used as a storage medium between the different steps of the study ${ }^{(18)}$. The roots of the teeth were removed and then the crowns of teeth were cut longitudinally in mesio-distal direction to expose the labial portion using diamond disc ${ }^{(15-16)}$.

Custom made plastic cylindrical molds were made and self-cured acrylic resin was poured inside the molds ${ }^{(15)}$. Each tooth-half was fixed with superglue on the custom made acrylic block so that the buccal side of each was available, and assigned a serial number from 1 to 40 . The labial surfaces were polished sub-sequentially starting from 600grit abrasive paper discs up to 1200 grit under water irrigation to produce flat enamel surfaces ${ }^{(16-19)}$. Enamel samples were divided equally into two groups according to the material used $\left(\mathrm{A}_{1}\right),\left(\mathrm{A}_{2}\right)$ and further subdivided into four subgroups according to the number of applications $\left(\mathrm{A}_{1} \mathrm{~B}_{1}\right),\left(\mathrm{A}_{1} \mathrm{~B}_{2}\right),\left(\mathrm{A}_{2} \mathrm{~B}_{1}\right)$ and $\left(\mathrm{A}_{2} \mathrm{~B}_{2}\right)$.

AFM study: The microstructure of enamel was investigated by AFM for all the specimens before starting experimentation (native enamel), after de- mineralization, and after 1week of re-mineralization. The samples of subgroups $A_{1} B_{1}$ (Curodont single application) and $\mathrm{A}_{2} \mathrm{~B}_{1}$ (Fluoride single application) were examined by AFM after 1 week from the application of the agents and the results of the average roughness were recorded in tables. Samples of subgroups $\mathrm{A}_{1} \mathrm{~B}_{2}$ (Curodont double application) and $\mathrm{A}_{2} \mathrm{~B}_{2}$ (Fluoride double application) were received the second application of the re-mineralizing agents and then left in the artificial saliva for another 1 week before examination by AFM and the average roughness of these subgroups were then recorded.

Invivo study: Twenty children ranging from 1016 years of age were selected from the Pedodontic clinic, faculty of Dental medicine for Girls, AlAzhar University. This study was approved by the research ethics committee of faculty of Dental Medicine for girls Al-Azhar University (protocol number Rec16:60). The procedure, possible discomfort $\&$ benefits were explained to the parents \& participants. Informed consent was obtained from the parents prior to the study.

\section{The inclusion criteria:}

- Children with at least 2 white lesions (WSL) detected clinically on the buccal surface of permanent anterior teeth, one on each side.WSL selected either due to caries or orthodontic treatment (just following deboning) $^{(4,13)}$.

- Children willing to keep good oral hygiene throughout the study ${ }^{(6)}$.

- Teeth with score1, 2, 3 according to ICDAS ${ }^{(13)}$.

- Absence of preoperative pain, no mobility and tenderness on percussion ${ }^{(20)}$.

- Radiographically, the pre-operative inclusion criteria were: absence of internal or external resorption, no periapical radiolucencies and no widening of periodontal ligament space. ${ }^{(20)}$ 


\section{The exclusion criteria:}

- Teeth with score 4, 5 according to ICDAS II ${ }^{(13)}$.

- Children with any medical or dental conditions that could impact the study results during its expected length ${ }^{(6)}$.

- Children who currently received extensive fluoride regiments for treatment of WSL ${ }^{(6)}$.

- Patients who planned to move within 6 months of enrollment ${ }^{(21)}$.

\section{Radiographic assessment}

Standardized reproducible periapical radiographs for each treated tooth were obtained using an indirect digital image plate which is part of Vista Scan System. Assessment of remineralization was done using measurements of radiodensity (\%). The measurement was performed by drawing a line parallel to the long axis of the selected tooth, dividing it into two halves starting from cementoenamel junction (CEJ) (as a reference point) to half the distance from CEJ to the incisal edge. Three points along this line (at its start, middle and end) were determined. The average of readings was taken to represent the radiodensity at the lesion area. This linear measurement was recorded in present (\%) for each selected tooth at base line "prior treatment" and 6 months after treatment to determine the degree of remineralization within the 4 subgroups.

Grouping: After examination, the patients were randomly assigned into 2 groups according to the re-mineralizing agent applied. $\mathbf{A}_{\mathbf{1}}$ : (20) white spot lesions re- mineralized with Curodont. $\mathbf{A}_{2}$ : (20) white spot lesions re-mineralized with Fluoride varnish. A split mouth design was followed so that each patient will be treated in one side by one application $\left(B_{1}\right)$ and on the other side by double applications $\left(B_{2}\right)$. Each group was further subdivided into 2 subgroups according to the number of applications with $\left(\mathrm{A}_{1} \mathrm{~B}_{1}\right)$ :10 WSL treated with Curodont single application, $\left(\mathrm{A}_{1} \mathrm{~B}_{2}\right)$ : $10 \mathrm{WSL}$ treated with Curodont double applications, $\left(\mathrm{A}_{2} \mathrm{~B}_{1}\right)$ : $10 \mathrm{WSL}$ treated with fluoride single application and $\left(\mathrm{A}_{2} \mathrm{~B}_{2}\right): 10 \mathrm{WSL}$ treated with fluoride double applications

\section{Application of the re-mineralizing agent:}

\section{$A_{1}-$ Curodont Repair (SAP P11-4):}

The surface of the carious lesion was cleaned using cotton wetted with $2 \%$ sodium hypochlorite $(\mathrm{NaOCl})$ for 20 seconds. $\mathrm{NaOCl}$ used for the removal of the organic debris and dissolution of the pellicle ${ }^{(12-13)}$. The surface was then etched with $37 \%$ phosphoric acid gel for 20 seconds to open the pores into the subsurface cavity in order to facilitate successful treatment with Curodont ${ }^{(4,12-13)}$. Finally, thorough rinsing with water (20 seconds) and air drying of the lesion surface were done.

Technique of application: Curodont was reconstituted with $50 \mathrm{ml}$ of sterile water. The tooth surface was air dried, and a drop of Curodont applied onto it using special syringe.The drop was left on the tooth for up to 5 minutes. The remainder of Curodont solution was rinsed off ${ }^{(12)}$.

\section{$A_{2}$ - Enamelast (Fluoride varnish):}

Enamelast $^{\circledR}$ is a flavored, xylitol-sweetened, $5 \%$ sodium fluoride in a resin carrier. Its formula is made with a patented adhesion-promoting agent for enhanced retention, providing superior fluoride release and uptake as claimed by the manufacturer.

Technique of application: In the unit dose, each blister pack includes a prefilled well and an applicator brush. The brush was simply dipped in the well. Teeth were lightly dried and painted with the varnish. In the syringe dose, the flow of the syringe was verified prior to applying intraorally. Teeth were lightly dried. The varnish was applied directly through the tip onto the teeth, before painting it on the teeth. Cheeks, lips and saliva were allowed to contact teeth as varnish hardens upon contact with saliva. Follow up was done at base line and after 6 months. 


\section{Statistical analysis}

Values were presented as mean and standard deviation (SD) values. Data were explored for normality using Kolmogorov-Smirnov test of normality. The results of Kolmogorov-Smirnov test indicated that most of data were normally distributed (parametric data), so parametric tests were used.The percent change in radiodenisty was calculated by the following formula

$\frac{\text { Value after- value before }}{\text { Value before }} \quad$ X 100

One way analysis of variance (ANOVA) test was used to compare between different intervals within the same group, followed by Tukey's post hoc test when the difference was found to be significant. Unpaired $t$ test was used for comparison between 2 independent groups.

\section{RESULTS}

\section{Results of the in vitro study (average roughness):}

The greatest mean roughness of re-mineralized enamel was recorded in group $\mathrm{A}_{2} \mathrm{~B}_{1}$ (fluoride single application) and $\mathrm{A}_{2} \mathrm{~B}_{2}$ (fluoride double application), followed by group $A_{1} B_{1}$ (Curodont single application), with the least value recorded in $\mathrm{A}_{1} \mathrm{~B}_{2}$ (Curodont double application) (Figure 1). Unpaired $\mathrm{t}$ test revealed no significant difference between single or double application within the same treatment.

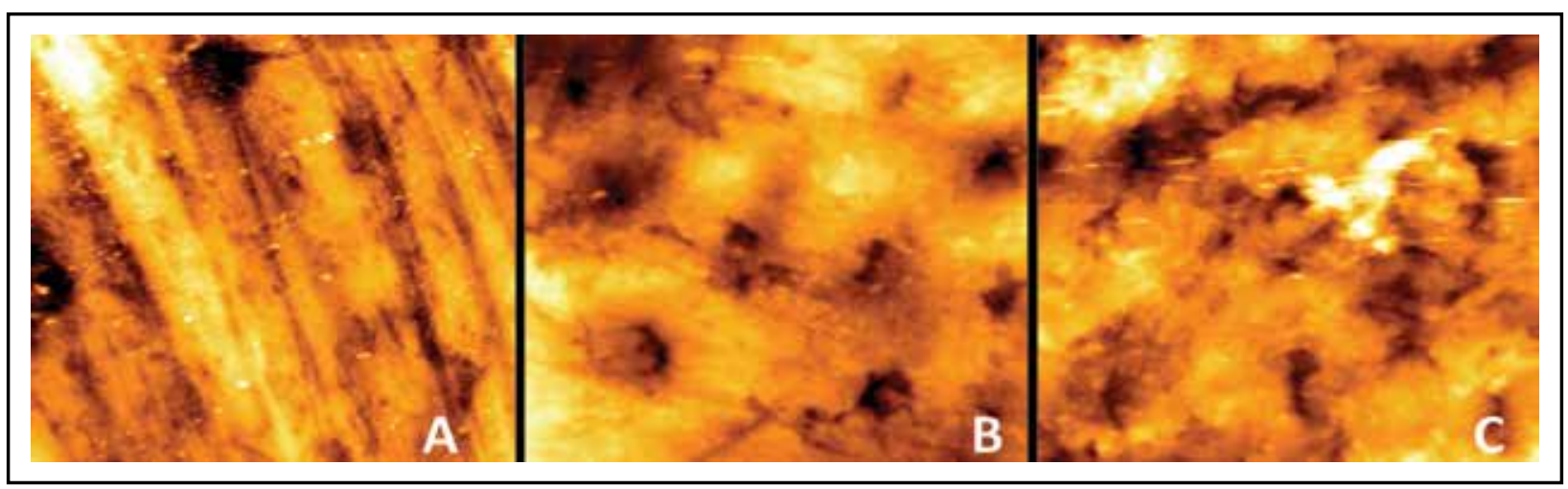

Fig. (1) 2D AFM Image showing(A): native enamel (B) :after demineralization (C): after Curodont application showing adherent deposits (tactoid-shaped material)

\section{Results of the In vivo study}

\section{Changes in the ICDASII scores:}

ANOVA test revealed no significant difference between groups at baseline, and after 8 or 12 weeks of application of the remineralizing agent. However after 6 months, significantly lower scores were recorded in group $A_{1} B_{2}$ (the least value) and group $A_{1} B_{1}$. ANOVA test revealed a significant difference betweenCurodont and fluoride groups after 6 months $(\mathrm{p}=0.024)$. Tukey post hoc test revealed no significant difference between both fluoride varnish subgroups. Although the lowest score was recorded in $A_{1} B_{2}$, it didn't significantly differ from $A_{1} B_{1}$ subgroup

\section{Comparison between radiodensity percentage of teeth before \& after 6 months within the different subgroups:}

Both subgroups of Curodont repair revealed an extremely higher percent increase of radiodensity percentage in comparison to both subgroups of fluoride varnish. ANOVA test revealed a significant difference between subgroups $(\mathrm{P}<0.0001)$. Unpaired $t$ test revealed no significant difference between single and double application of the same remineralizing agent (table1). 
Table (1) Percent increase of radiodensity percentage before and after application of the remineralizing agent on WSLs and comparison between both subgroups of the same remineralizing agent (unpaired t-test) and between all groups (ANOVA test)

\begin{tabular}{|l|c|c|c|c|}
\hline Percent increase of radio density percentage & A1B1 & A1B2 & A2B1 & A2B2 \\
\hline Mean & $47.92^{\mathrm{a}}$ & $46.56^{\mathrm{a}}$ & $14.40^{\mathrm{b}}$ & $15.66^{\mathrm{b}}$ \\
\hline SD & 10.72 & 16.41 & 4.72 & 6.81 \\
\hline Min & 35.59 & 16.67 & 5.51 & 6.45 \\
\hline Max & 65.00 & 89.00 & 23.00 & 30.85 \\
\hline t value (unpaired t test) & \multicolumn{2}{|c|}{0.2596} & \multicolumn{3}{|c|}{0.5268} \\
\hline P value (between subgroups of the same agent) & \multicolumn{3}{|c|}{$\mathbf{0 . 7 9 7 2}^{\text {ns }}$} & \multicolumn{3}{|c|}{37.36} \\
\hline Fvalue (ANOVA test) & \multicolumn{3}{|c|}{$\mathbf{0 . 0 0 0 1}^{\text {* }}$} \\
\hline P value (between all subgroups) & \multicolumn{3}{|c|}{} \\
\hline
\end{tabular}

\section{3- Comparison between both remineralizing agents regarding the change of $P H$ of saliva:}

Unpaired t test revealed no significant difference between both groups at baseline,after 3 months and after 6 months (table 2).

Table (2) Comparison between different groups regarding $p H$ change after application of the remineralizing agent and significance of the difference using unpaired t test

\begin{tabular}{|c|c|c|c|c|c|c|}
\hline & \multicolumn{2}{|c|}{ Baseline } & \multicolumn{2}{|c|}{ After 3months } & \multicolumn{2}{|c|}{ After 6 months } \\
\hline & (A1) & (A2) & (A1) & (A2) & (A1) & (A2) \\
\hline Mean & 6.12 & 6.14 & 6.68 & 6.38 & 7.06 & 6.96 \\
\hline SD & 0.21 & 0.19 & 0.25 & 0.22 & 0.28 & 0.25 \\
\hline Min & 5.80 & 5.80 & 6.20 & 6.20 & 6.60 & 6.60 \\
\hline Max & 6.40 & 6.40 & 7.00 & 6.80 & 7.40 & 7.40 \\
\hline $\mathrm{t}$ value & \multicolumn{2}{|c|}{0.2446} & \multicolumn{2}{|c|}{1.1207} & \multicolumn{2}{|c|}{0.9229} \\
\hline P value & \multicolumn{2}{|c|}{$0.8090^{\text {ns }}$} & \multicolumn{2}{|c|}{$0.105^{\mathrm{ns}}$} & \multicolumn{2}{|c|}{$0.3661^{\mathrm{ns}}$} \\
\hline
\end{tabular}

\section{DISCUSSION}

This study was conducted to evaluate remineralization potential of the newly introduced self-assembling peptide P11-4 (Curodont) that provides a non-invasive option for guided enamel regeneration (GER) versus highly concentrated fluoride agent (Varnish) after single and double applications both in vitro (applied to artificially induced initial carious lesions in enamel) and in vivo (used for management of early carious lesions in enamel (WSL).

The tooth structure that was selected for this study was enamel rather than dentin because enamel is the first line of defense against caries progression. Although enamel is a hard and dense material, it possesses local differences in porosity and acid solubility; acids can penetrate deep into enamel and dissolve tooth minerals locally, rather than dissolving the enamel layer by layer ${ }^{(17)}$. Therefore, remineralization of early enamel lesions is of great value to protect other dental tissues.Moreover, it was found that dentin remineralization is more difficult than enamel remineralization due to the abundant presence of organic matrix in dentine ${ }^{(22)}$. 
Results of AFM of this study showed that all the samples at the pretreatment phase (native enamel), appeared smooth and free from cracks and porosities. The base line $\mathrm{Ra}$ of the present study was with a range of $80-88 \mathrm{~nm}$ which was similar to many studies ${ }^{(22-23)}$. There was no significant difference in the average roughness $(\mathrm{Ra})$ between all subgroups.

The demineralized enamel surface appeared much rougher in the two dimensions images. Demineralized areas were in the form of wide erosion cavities and narrow porosities. This pattern of demineralization might be due to the fact that the enamel surface is a homogenous, structureless and a prismatic $^{(17-18)}$, or as a result of collection of narrow porosities which might lead to the presence of wide erosion cavities. This agreed with several studies who found that enamel after demineralization appeared eroded and with a high degree of surface porosity showing a honeycomb-like structure ${ }^{(17)}$. This morphological aspect was reflected in the values of Ra which increase significantly from $88 \mathrm{~nm}$ of intact enamel to about $178 \mathrm{~nm}$ of demineralized enamel. However there was no significant difference in (Ra) between all samples after demineralization.

After application of the tested remineralizing agents, the samples appeared with adherent irregularities and globular deposits. This AFM image was similar to the features of another AFM study ${ }^{(24)}$ that described a homogenous layer covering the eroded areas of enamel. The average roughness $(\mathrm{Ra})$ of all samples of both groups significantly decreased. Results of $\mathrm{Ra}$ also showed that the lower mean values of enamel roughness were seen in group $\mathrm{A}_{1}$; Curodont $(107.81 \mathrm{~nm}$ and $95.32 \mathrm{~nm})$ denoting higher remineralization efficacy than group $\mathrm{A}_{2}$; fluoride $(114.77 \mathrm{~nm}$ and110.44nm).However, there was no significant difference between single or double applications within the same group. This insignificant difference may be attributed to the short time of remineralization procedure.

Regarding to the percent of decrease the greatest mean percent decrease of Ra was seen in subgroup-
$\mathrm{A}_{1} \mathrm{~B}_{2}$ (curodont double applications) (27.71\%) followed with $\mathrm{A}_{1} \mathrm{~B}_{1}$ (Curodont single application) and $\mathrm{A}_{2} \mathrm{~B}_{2}$ ( $\mathrm{F}$ double application) with similar percent decrease in roughness $(16.98 \%$ and $16.62 \%$ respectively), and the least percent decrease (12.48\%) was in $A_{2} B_{1}$ (Fluoride single application). This might be due to the low viscosity of Curodont enabling it to penetrate into the micro pores of surface, triggering a process of self-assembly and generating a bioactive scaffold that determines the deposition of minerals in situ. Curodont repair is a product that incorporates the P11-4-based technology, together with fluoride and calcium phosphate ${ }^{(25)}$. Therefore, Curodont produced constant and stable remineralization of all demineralized areas, allowing continuous minerals supply for the tooth, which filled deeply in the porosities formed after demineralization.

The results of Curodont group, agreed with the results of another study ${ }^{(26)}$ showed that with Curodont it was possible to achieve visual and microscopic changes in artificially created enamel lesions stored in a remineralizing medium. Moreover, the results of the $\mathrm{Ra}$ of the present study came in accordance with a study that found significant reduction in enamel roughness values on comparing eroded enamel and eroded enamel treated with Curodont ${ }^{(25)}$.

Fluoride varnish in the present study reduced also the surface roughness of enamel. This was because F.varnish acted as a mineral reservoir supplying the tooth slowly with fluoride and minerals which filled in porosities formed after demineralization and enhancing remineralization. The results of fluoride varnish may be due to Calcium Fluoride $\left(\mathrm{CaF}_{2}\right)$ deposited as a result of fluoride topical application. $\mathrm{CaF}_{2}$ act as a reservoir that releases fluoride when the $\mathrm{pH}$ falls to very low level, proving that $\mathrm{CaF}_{2}$ has a great impact on remineralization ${ }^{(16)}$.

Results of the in vivo study showed that: patients in all subgroups showed gradual decrease of ICDAS scores from the base line to reach the lowest level after 6months. Results revealed no significant difference between groups at baseline, and after 
8 and 12 weeks of application of the remineralizing agent. However, there was a significant difference between groups $\left(\mathrm{A}_{1}\right.$; Curodont $)$ and $\left(\mathrm{A}_{2}\right.$; Fluoride $)$ after 6 months $(\mathrm{p}=0.024)$.After 6 months, the significantly lower scores were recorded in Curodont subgroups; $\mathrm{A}_{1} \mathrm{~B}_{2}$ (the least value) and $\mathrm{A}_{1} \mathrm{~B}$. Although the lowest score was recorded in $\mathrm{A}_{1} \mathrm{~B}_{2}$, it didn't significantly differ from $A_{1} B_{1}$ subgroup. Therefore, after 6 months (the time length of the study), the lowest scores were recorded in subgroup (Curodont double application) followed by (Curodont single application).There was no statistical difference between single and double application in both Curodont subgroups and fluoride varnish subgroups.

Regarding the Curodont, the results of this study proved that Curodont group was able to achieve visual improvement of WSLs. These results came in accordance to an in vivo study ${ }^{(9)}$ that achieved promising results with a prototype of Curodont applied on Class V cavities after just one application of this peptide.

The visual and clinical results of the Curodont in the present study was in accordance also to a study $^{26}$ that showed better visual and microscopic changes in Curodont group than in control group.

Regarding the fluoride, the visual and clinical results came in accordance to some scholars ${ }^{(27)}$ who found that the use of high local doses of fluoride had no effect on the size of the arrested lesion and can allow it to acquire unsightly staining with organic debris.This may be because highly concentrated fluoride induced hypermineralization and staining of teeth.

Regarding to radiodensity percentage, the measurements were recorded at 2 time intervals at the base line (before application of the remineralizing agents) and after 6months of application. Both subgroups of Curodont repair $\left(\mathrm{A}_{1} \mathrm{~B}_{1}, \mathrm{~A}_{1} \mathrm{~B}_{2}\right)$ revealed a significantly higher percent increase $(47.92 \%$, $46.56 \%$ ) in comparison to fluoride subgroups $(14.4 \%, 15.66 \%)$. There was no significant difference between single and double applications within the same treatment.
These results come in accordance with a study (12) concluded that the biomimetic mineralization offers, for the first time, the possibility to reform lost enamel crystals underneath the surface. This study assessed the carious lesions both radio graphically and visually. Assessment of the caries lesions after 6 months of Curodontwith standardized radiographs compared to baseline showed: $42.3 \%$ regression, meaning visible in-depth mineralisation of the lesion; $43.6 \%$ unchanged size of the lesion, $23.1 \%$ of the lesion showing progression.

Salivary $\mathrm{pH}$ was a parameter characterizing oral cavity environment and was assessed in this study using ' Saliva-Check Buffer kit". The change in the $\mathrm{pH}$ of saliva was checked with the $\mathrm{pH}$ strips and $\mathrm{pH}$ indicator at 3 intervals at baseline, after 3 months and after 6 months.

According to our results there was a gradual increase in the $\mathrm{pH}$ of saliva in both Curodont and $\mathrm{F}$ group after 3 and 6 months. However, there was no significant difference between the Curodont and fluoride group, showing that the effect of both remineralizing agents on the $\mathrm{pH}$ of saliva was comparable. This might be due to the fact that the application of the remineralizing agent was not an enough factor to neutralize the $\mathrm{pH}$ of saliva but neutralization of saliva is a multifactorial process, including patient oral hygiene, diet control, sugar consumption etc. Therefore, the increase of $\mathrm{pH}$ of saliva in both groups could be related to the effect of prophylaxis performed, motivation and oral hygiene instructions.

The mean salivary $\mathrm{pH}$ values observed in this study both at baseline (6.12and 6.14) and after 6 months (7.06 and6.96) were lower compared to the values reported ${ }^{(28)}$. This may be due to the older age patients (20-30years) in their study.

\section{CONCLUSION}

1. Self-assembling peptides (Curodont repair) was successful as a remineralizing agent in young permanent teeth with white spot lesions. 
2. Both remineralizing agents had similar effect on enamel roughness.

3. There are correlations between clinical and in vitro study showing the superiority of the new material Curodont(SAP P11-4) over the gold standard fluoride.

\section{REFERENCES}

1. Featherstone JD. The continuum of dental caries- evidence for a dynamic disease process. J Dent Res 2004; 83:39-42.

2. Tencate JM.Remineralization of deep enamel dentine caries lesions. Australian Dent J Association 2008; 53:281285.

3. Marinho VC, Higgin SJP, Logan S, Sheiham A. Topical fluoride (tooth pastes, mouth rinses, gels or varnishes) for preventing dental caries in children and adolescents. Cochrane Database Syst Rev 2004; 4:72-82.

4. Bróseler F, Tietmann C, Schleich R, Drechsel T, Bommer C. Effect of Curodont Repair in patients with buccal carious lesions: a mono- center, single -blinded, randomized, controlled, Split mouth study -Intermediate report. Clin Oral Invest 2013;17: 1055.

5. Sinch RA, Bichu YM, and Narkhede SP. White spots on teeth or black marks on treatment results .A contemporary review of enamel demineralization during fixed orthodontic treatment. Inter J Med Clin Res2013; 4:263-268.

6. Robertson MA, Kau CH , English JD , Lee RP, Powers J Nguyen JT. MI paste plus to prevent demineralization in orthodontic patients : A prospective randomized controlled trial .Am J Orthodontics \&Dentofacial Orthopedics 2011; 140: $660-668$.

7. Bilbilova EZ, Popovska L, Kapusevska B, Stefanovska E. White spot lesions: Prevention and management during the orthodontic treatment. MAHY MASA 2014:161-68.

8. Kirkham J, Firth A, Venrnals D, Boden N, Robinson C, Shore RC, Brookes SJ, and Aggeli A. Self-assembling Peptide Scaffolds Promote enamel remineralization. J Dent Res 2007; 86: 426-430.

9. Brunton PA, Davies R.P.W, Burke J.L, smith A , Aggeli A, Brookes SJ , and Kirkham J. Treatment of early caries lesions using biomimetic self-assembling peptides: A clinical safety trial. Brit Dent J 2013; 215-221.

10. Aggeli A, Bell M, Carrick LM et al. PH as a trigger of peptide beta-sheet self-assembly and reversible switching between nematic and isotropic phases. J Am ChemSoc 2003; 125:9619- 9628 .

11. Kirkham J, Brookes SJ, shore RC, wood SR, smith DA, zhang J, et al. Physico - chemical properties of crystal surfaces in matrix mineral interactions during mammalian bio mineralization.Curropin colloid interface sci 2002.7:124-132.

12. Schlee M, Rathe F, Huck T, Til S, Jan H. Koch, Tjaden A, Bommer C.Clinical effect of biomimetic mineralization in approximal caries.Interim Results of a clinical study after 6 months.Stomagologie2014; 111:175-181.

13. Alkilzy, M; et al. "Efficacy, Clinical Applicability and Safety, of CurodontTM Repair in Children with Early Occlusal Caries". Caries Res 2015;49:311. doi:10.1159/0 00381323'

14. Chen X, Gillam D.G, Lysek D.A, Hill R.G . "In Vitro Evaluation of Dentine Remineralisation by a SelfAssembling Peptide Using Scanning Electron Microscopy" .Caries Res 2014; 48: 402. doi:10.1159/000360836

15. Lata S, Varghese NO and Varughese JM.Remineralization Potential of Fluoride and amorphous Calcium PhosphateCasein Phosphopeptide on enamel lesions: An in vitro comparative evaluation. J Conserv Dent 2010; 13(1) 42-46.

16. Lippert F, Parker D.M, Jandt K.D. In vitro demineralization /remineralization cycles at human tooth enamel surfaces investigated by AFM and nanoindentation. $\mathrm{J}$ of .colloid and interface science 2004; 442-48.

17. Zhou C, Zhang D, Bai Y, Li S. Casein phospho peptideamorphous calcium phosphate remineralization of primary teeth with early enamel lesions. JOD 2013; 42:21-29.

18. Poggio C, lombardini M, Dango A, Chiesa M, Bianchi S. Protective effect on enamel demineralization of a CPP ACP paste: an AFM in vitro study. JOD 2009; 949 - 54.

19. Poggio C,Lombardini M, Vigorelli P, Colombo M,Chiesa $\mathrm{M}$. The role of different toothpastes on preventing dentin erosion: An SEM and AFM study. Scanning 2012;1-10.

20. Niazy MA, Elmarsafy SMA and Nour El-Deen MM: Clinical and radiographic evaluation of two tissue engineering materials (BioGen and Bioaggregate) as direct pulp capping agent in human teeth. Cairo Dental J 2011; 27(1):17-26.

21. Almosa NA, Lundgren T, Bresini A, Birkhed D \&Kjellberg H. Diagnosing the severity of buccal caries lesions in orthodontic patients at de-bonding using digital photographs.ActaOdontologicaScandinavica2013;1-7. 
22. Zhang X, Neoh KG, Lin CC, Kishen A. Remineralization of partially demineralized dentine substrate based on biomimetic strategy. J Mater Sci Mater Med 2012; 23:733-742.

23. Quartarone E, Mustarelli P, Poggio C, Lombardini M. Surface kinetic roughening caused by dental erosion: An atomic force microscopy study. J ApplPhys 2008; 103:1047-52.

24. Medeiros IC, Brasil VLM, Carlo HL, Dos Santos RL, De Lima BAS, and De Carvalho FG. In vitro effect of calcium nanophosphate and high concentrated fluoride agents on enamel erosion: An AFM study. Int. J. Pediatr Dent, 2013;1-7.

25. Ceci M, Mirando M, Beltrami R, Chiesa M, Colombo M Poggio C.Effect of Self-Assembling Peptide P11-4 on Enamel Erosion: AFM andSEM Studies. Scanning 2015;DOI: $10.1002 /$ sca.21276.

26. Jablonski-Momeni A, Heinzel-Gutenbrunner M. Efficacy of the self-assembling peptide P11-4 in constructing a remineralization scaffold on artificially-induced enamel lesions on smooth surfaces. J OrofacOrthoped 2014; 75: 175-190.

27. WANG Jun-xiang, YANY Yan and WANG Xiu-Jing. Clinical evaluation potential of casein phosphopetide amorphous calcium phosphate nanocomplexes for enamel decalcification in orthodontics. Chin Med 2012;125 (22):4018-4021.

28. Surdackaa A, Strzykałab K, Rydzewskac A. Changeability of oral environment. Eur J Dent2007; 1:14-17. 